\title{
EFFECT OF CATECHOLAMINES AND OVARIAN HORMONES ON CYCLIC AMP ACCUMULATION IN RAT HYPOTHALAMUS*
}

\author{
K.P. Gunaga** and K.M.J. Menon ${ }^{+}$ \\ Reproductive Endocrinology Program \\ Departments of Obstetrics and Gynecology \\ and Biological Chemistry \\ The University of Michigan Medical Center \\ Ann Arbor, Michigan 48104
}

Received June 14, 1973

\section{SUMMARY}

Effect of different monoamines and estradiol were studied on cyclic AMP (CAMP) accumulation in hypothalami from 21 day old female rats. Incubation for $5 \mathrm{~min}$ with $10^{-4} \mathrm{M}$ epinephrine, norepinephrine or dopamine resulted in an increase in CAMP accumulation in the hypothalamus. Incubation of hypothalamic tissue with estradiol $\left(4 \times 10^{-7} \mathrm{M}\right.$ to $\left.2 \times 10^{-5} \mathrm{M}\right)$ also resulted in an increase in cyclic AMP levels. The increase caused by estradiol was observod only after $50 \mathrm{~min}$ of incubation period. The estradiol induced increase in cyclic AMP accumulation was abolished by both $\alpha$ and $\beta$ blockers. These results suggest that the estradiol-induced increase in cyclic AMP may be mediated by a prior increase in catecholamines in the hypothalamic tissue.

Monoaminergic participation in the control of ovulation and gonadal function has been suggested (1-3). The level of dopamine and norepinephrine in the hypothalamus have been shown to change in different physiological conditions associated with altered gonadotropin secretion (4). Dopamine has been shown to elevate follicle stimulating hormone and luteinizing hormone release both in vitro and in vivo by stimulating the release of hypothalamic gonadotropin releasing factors (5-8). Epinephrine was reported to be the most effective catecholamine to induce ovulation (9).

\footnotetext{
* Supported by a program project in Reproductive Endocrinology from NIH (HD 05318)。

**Postdoctoral fellow of the Ford Foundation.

$t_{\text {To }}$ whom correspondence should be addressed.
} 
There is also evidence that pituitary function, significantly affected by ovarian hormones, is mediated through adrenergic and serotoninergic pathways $(4,10-13)$.

These observations prompted an investigation on the effects of catecholamines and ovarian steroids on hypothalamic cyclic AMP leyels as cyclic AMP has been shown to mediate the action of catecholamines in a variety of tissues.

\section{MATERIALS AND METHODS}

Chemicals: L-Epinephrine, L-Norepinephrine bitartrate, Dopamine HCl, Serotonin creatinine sulfate complex and DL-propranolol HCl were purchased from Sigma Chemical Co. Phentolamine (Regitine) was a product of CIBA. Crystalline estradiol was purchased from Steraloids.

Procedure: 21 day old female rats (Holtzman) were used in this study. The rats were sacrificed and the hypothalami were immediately removed and put in cold Krebs-Ringer Bicarbonate buffer, pH 7.4 containing $0.2 \%$ glucose (KRBG) . Hypothalami were preincubated in $1.0 \mathrm{ml} \mathrm{KRBG}$ for $45 \mathrm{~min}$ at $37^{\circ} \mathrm{C}$ under $95 \% \mathrm{O}_{2}-5 \% \mathrm{CO}_{2}$ to deplete the levels of endogenous catecholamines, as suggested by Kakiuchi and Rall (14). After 45 min of preincubation, the incubation medium was replaced by $1.0 \mathrm{ml}$ fresh KRBG and additions were made as indicated under individual experiments. At the end of the incubation period, the medium was quickly discarded and $1.0 \mathrm{ml}$ of $5 \%$ trichloracetic acid was added to each tube containing the hypothalamic tissue, homogenized and centrifuged at $7000 \mathrm{rpm}$ for $10 \mathrm{~min}$ and cyclic AMP was determined in the super- 
natant as described by Gilman (15). Results represent the average values of minimum three observations in each group. $P$ values are calculated using student ' $t$ ' test.

\section{RESULTS AND DISCUSSION}

Incubation of rat hypothalamus with $10^{-4} \mathrm{M}$ norepinephrine resulted in a significant increase $(p<0.05)$ in cAMP as early as $2.5 \mathrm{~min}$. The optimum response of about $75 \%$ was observed after 5 min incubation which fell to $57 \%$ after 15 min incubation (Fig

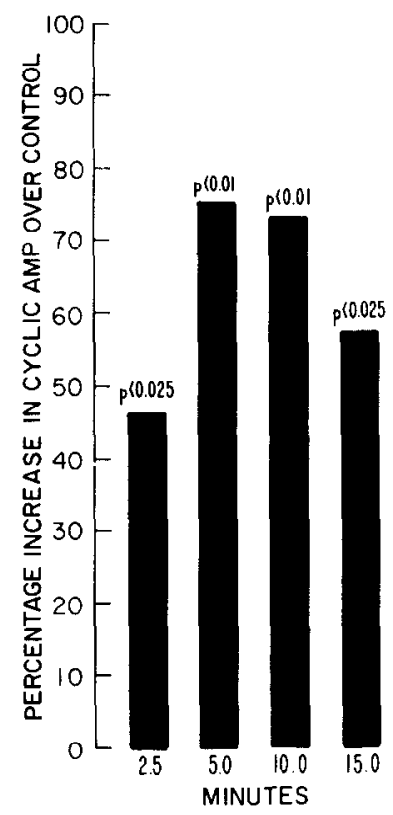

Fig 1. Time course studies on the effect of norepinephrine on rat hypothalamic CAMP level: After preincubation as described in the text, hypothalami were incubated in $1 \mathrm{ml} \mathrm{KRBG}$ containing $10^{-4} \mathrm{M}$ norepinephrine in $20 \mu 1$ saline. Control tubes contained $1 \mathrm{ml}$ KRBG with $20 \mu 1$ saline.

1). It was also observed that the incubation of hypothalamus for 5 min with $10^{-4} \mathrm{M}$ of norepinephrine, epinephrine or dopamine re- 
sulted in $52 \%(\mathrm{p}<0.05), 36 \%(\mathrm{p}<0.025)$ and $32 \%(\mathrm{p}<0.025)$ increase in CAMP, respectively, over the control. Serotonin at $10^{-4} \mathrm{M}$ concentration did not alter the cyclic AMP levels in hypothalamus (Fig 2).

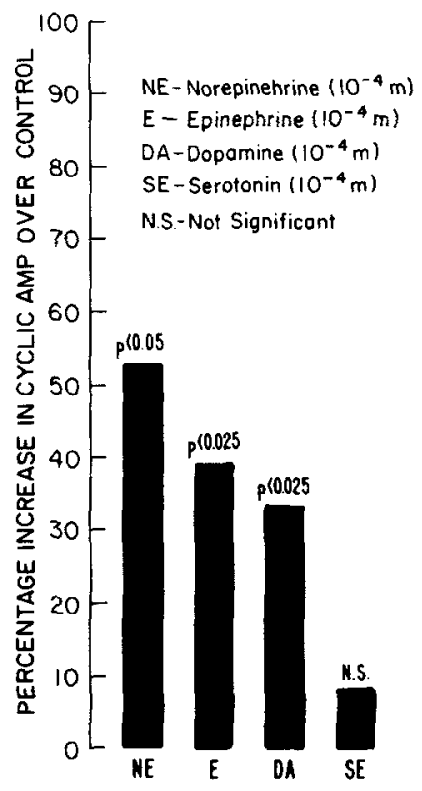

Fig 2. Effect of different monoamines on rat hypothalamic CAMP level: After preincubation, hypothalami were incubated for 5 min with $1 \mathrm{ml}$ KRBG and $20 \mu 1$ saline containing $10^{-4} \mathrm{M}$ norepinephrine, epinephrine, dopamine or serotonin. control tubes contained $1 \mathrm{ml}$ KRBG with $20 \mu 1$ of saline.

When hypothalamic tissues were separately incubated with varying concentrations of estradiol (4 $\mathrm{x} 10^{-9} \mathrm{M}$ to $\left.4 \times 10^{-3} \mathrm{M}\right)$, an increase in CAMP was observed at $4 \times 10^{-7} \mathrm{M}$ and optimal stimulation was observed at $2 \times 10^{-5} \mathrm{M}$. At optimal concentration of estradiol $\left(2 \times 10^{-5} \mathrm{M}\right)$, an increase in cAMP accumulation was observed after $50 \mathrm{~min}$ of incubation period and reached maximum at 70 min after which it declined (Fig 3). 


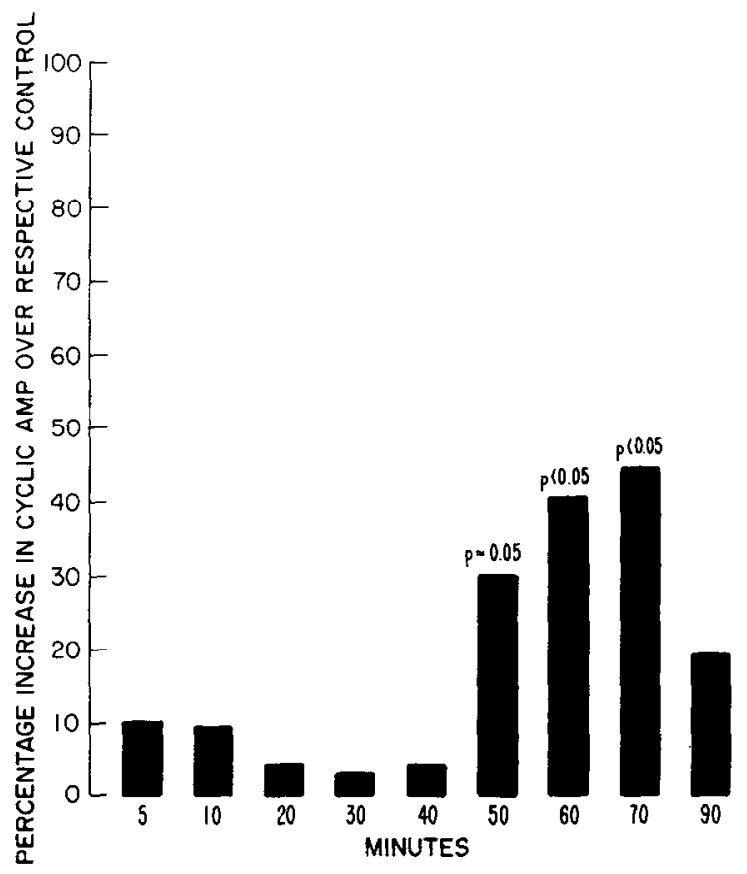

Fig 3. Time course studies on the effect of estradiol on rat hypothalamic CAMP level: After preincubation, hypotha1ami were incubated in $1 \mathrm{ml}$ KRBG with $20 \mu 175 \%$ ethanol containing $2 \times 10^{-5} \mathrm{M}$ estradiol. Control tubes contained $1 \mathrm{mI} \mathrm{KRBG}$ with $20 \mathrm{HI} 75 \%$ ethanol.

Effect of theophylline, an inhibitor of phosphodiesterase, on estradiol-induced accumulation in hypothalamic cAMP is shown in Fig 4 . Theophylline at $10^{-4} \mathrm{M}$ concentration slightly increased CAMP accumulation. Theophylline along with estradiol induced an additional increase in CAMP in hypothalamus as compared to the stimulation of hypothalamic cAMP level caused by estradiol alone (Fig 4) .

These results demonstrate that estradiol causes an increase in hypothalamic cAMP content. However, estradiol-induced increase in CAMP is a delayed effect as compared to early increase 


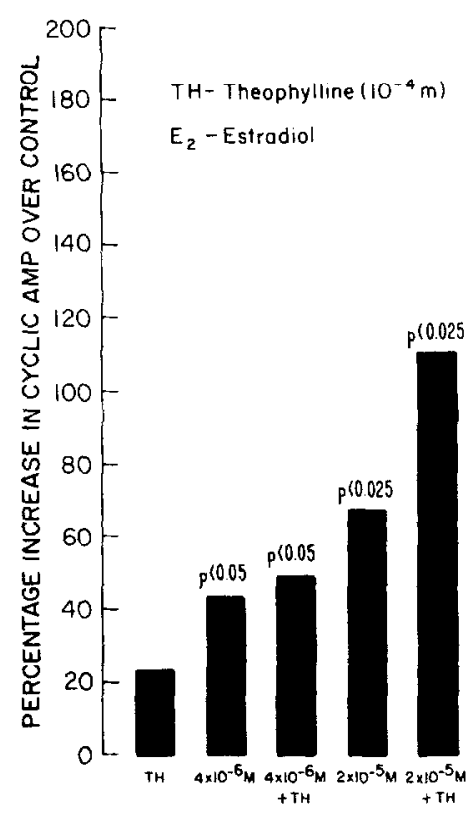

Fig 4. Effect of estradiol and estradiol plus theophylline on the rat hypothalamic cAMP level: After preincubation, hypothalami were incubated with $1 \mathrm{ml}$ KRBG with $20 \mu \mathrm{l}$ $75 \%$ ethanol containing $4 \times 10^{-6} \mathrm{M}$ or $2 \times 10^{-5} \mathrm{M}$ estradiol alone or along with $20 \mu l$ of distilled water containing $10^{-4} \mathrm{M}$ theophylline. Control tubes contained $1 \mathrm{ml} \mathrm{KRBG}$ and $20 \mu 175 \%$ ethanol. Other groups contained $1 \mathrm{ml}$ KRBG with $20 \mu 175 \%$ ethanol and $20 \mu 1$ of $10^{-4} \mathrm{M}$ theophylline.

brought about by catecholamines. Many studies have shown that the turnover of catecholamines in the hypothalamus as well as in the brain is related to the availability of gonadal steroids (4, 16-19). Thus it is possible that estradiol-induced CAMP accumulation may be preceded by an early increase of catecholamines. A similar phenomenon has been observed by others on the effect of estradiol on uterine cAMP levels $(20-21)$.

Both $\alpha$ and $\beta$ adrenergic blockers can overcome the estradiol effect on the elevation of hypothalamic CAMP (Fig 5). It is likely 


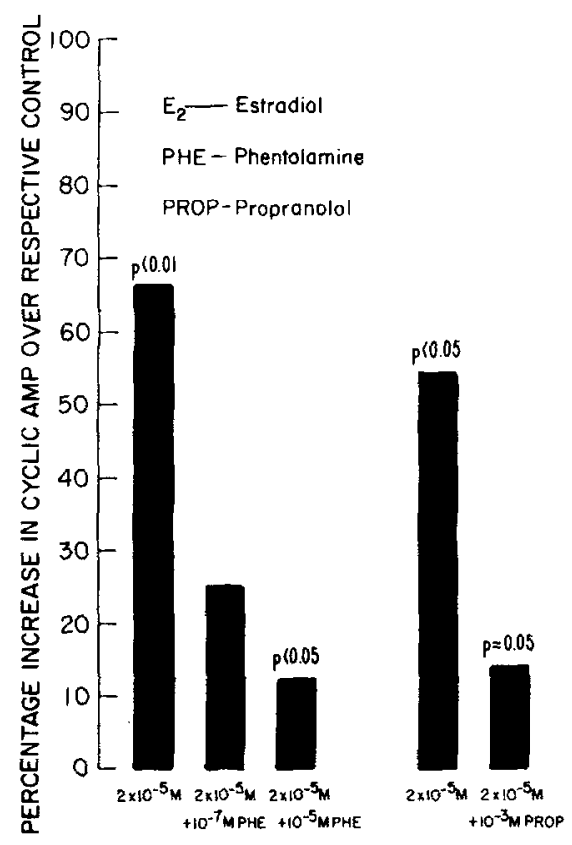

Fig 5. Effect of adrenergic blockers on estradiol induced increase in cAMP level in rat hypothalamus: After preincubation, hypothalami were incubated with $1 \mathrm{ml}$ KRBG with $20 \mu 175 \%$ ethanol containing $2 \times 10^{-5} \mathrm{M}$ estradiol alone or along with $20 \mu \mathrm{l}$ of saline containing $10^{-7} \mathrm{M}$ or $10^{-5} \mathrm{M}$ phentolamine or $10^{-3} \mathrm{M}$ propranolol. The following controls were included: 1) $1 \mathrm{mI} \mathrm{KRBG}$ with $20 \mu 175 \%$ ethanol and $20 \mu 1$ saline, 2) I mI KRBG with $20 \mu 1$ 75\% ethanol and $20 \mu 1$ saline containing $10^{-7} \mathrm{M}$ or $10^{-5} \mathrm{M}$ phentolamine or 3) I $\mathrm{ml} \mathrm{KRBG}$ in the $20 \mu \mathrm{I} 75 \%$ ethanol and $20 \mu \mathrm{I}$ saline containing $10^{-3} \mathrm{M}$ propranolol.

that these adrenergic blockers may lack specificity in blocking the specific adrenergic receptors in this tissue. It has been shown that propranolol which is a $\beta$-blocker caused blocade of the $\alpha$-receptor in the rabbit aortic strips (22). In guinea pig brain, cerebellum contains classical $\beta$-adrenergic receptors and the rest of the brain contains a-adrenergic receptors both of which mediate an increase in CAMP accumulation by catecholamines (23). It is 
also likely that increase in cAMP level brought about by estradiol may be through catecholamines influencing $\alpha$-receptors or the $\alpha$-receptors in turn influencing $\beta$-receptors through unknown mechanism(s). There are increasing number of studies on the possible role of catecholamines as neurotransmitter in the control of the release of gonadotropins by promoting the release of gonadotropin releasing hormone $(\mathrm{Gn}-\mathrm{RH})$. The results of the present study suggest a possible role of CAMP in the mediation of gonadal hormone - catecholamine system on the regulation of GnRH secretion at the hypothalamic level. In this context, it is interesting to note, that when high doses of dibutyryl CAMP was injected into certain regions of the hypothalamus resulted in hyperthermia, prolongation of estrous cycle and increased water intake $(24,25)$, further suggesting that cyclic nucleotide may have a regulatory role at the hypothalamic level.

\section{REFERENCES}

1. Sawyer, C.H., Markee, J.E. and Holinshead, W.H., Endocrinology 1,395 (1947).

2. Barraclough, C.A. and Sawyer, C.H., Endocrinology 61, 341 (1957).

3. Everett, JoW., physiol. Rev. 44,373 (1964).

4. Fuxe, K. and Hokfelt, T., In: 'Frontiers in Neuroendocrinology' (Eds.) Ganong, W.F. and Martini, L.; Oxford University Press, New York, 1969, pp. 47.

5. Schneider, H.P.G. and Mccann, S.M., Endocrinology 85, 121 (1969).

6. Schneider, H.P.G. and McCann, S.M., Endocrinology 87, 249 (1970).

7. Kamberi, I.A., Schneider, H.P.G. and McCann, S.M., Endocrinology 86, 278 (1970).

8. Kamberi, I.A., Mical, R.S. and Porter, J.C., Endocrinology 88,1003 (1971).

9. Rubinstein, L。, and Sawyer, C.H., Endocrinology 86, 988 (1970) .

10. Coppola, J.A., J. Reprod. Fertil. Suppl. 4 , 35 (1968). 
11. Donoso, A.G. and DeGuiterrez Moyano, Proc. Soc. Exp. Biol. Med. 135, 633 (1970).

12. Wurtman, R。J., In: 'Hypophysiotropic Hormones of the Hypothalamus: Assay and Chemistry', (Ed.) Meites, J., The Williams and Wilkins Co., Baltimore, 1970, pp. 184.

13. Kordon, C. and Glowinski, J., Neuropharmacology 11,153 (1972).

14. Kakiuchi, S. and Rall, T.W., Mol. Pharmacol. 4, 367 (1968).

15. Gilman, A.G., Proc. Nat1. Acad. Sci. U.S. 67, 305 (1970).

16. Anton-Tay, F., Anton, S., and Wurtman, R.J., Neuroendocrinology 6,265 (1970).

17. Bapna, J., Neff, N.H. and Costa, E.A., Endocrinology 89, 1345 (1971).

18. Donso, A.O. and Stefano, F.J.E., Experientia 23, 655 (1967).

19. Donso, A.O., Stefano, F.J.E., Biscardi, A.M. and Cukier, J. Amer. J. Physiol. 212, 737 (1967).

20. Szego, C.M. and Davis, J.S., Mol. Pharmacol. 5,470 (1969)。

21. Rosenfeld, M.G. and O'Malley, B.W., Science 168, 253 (1970).

22. Kohli, J.D. and Iing, G.M., J. Pharm。 Pharmacol. 19, 631 (1967).

23. Chasin, M., Rivkin, I., Mamrak, F., Samaniego, S.G. and Hess, S.M., J. Biol。 Chem. 246, 3037 (1971).

24. Breckenridge, B.M. and Iisk, R.D., Proc. Soc. Exp. Biol. Med. 131, 934 (1969).

25. Rindi, G., Sciorelli, G., Poloni, M. and Acanfora, F., Experientia 28, 1047 (1972). 